Faculdade de Ciências Econômicas UFRGS

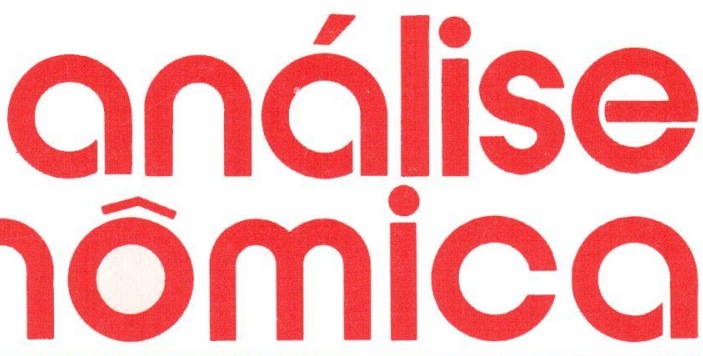

\title{
nesta edição:
}

- PANEGÍRICO DE ROBERTO' CAMPOS

Lauro Campos

- INFLAÇÃO: A HETERODOXIA TEORICA BRASILEIRA E A ORTODOXIA DA PRÁTICA ARGENTINA

Leda Maria Paulani

- AJUSTAMENTO MACROECONO̊MICO, RACIONAMENTO E EXPECTATIVAS RACIONAIS Nali de Jesus de Souza

- PRODUÇĀo E CONSUMO DE ALIMENTOS BÁSICOS NO BRASIL Antônio Miguel Bós

- CULTIVOS PARA MERCADO INTERNO VERSUS PARA EXPORTAÇÃo Arion C. Foerster, Juvir L. Mattvella e Judas Tadeu G. Mendes
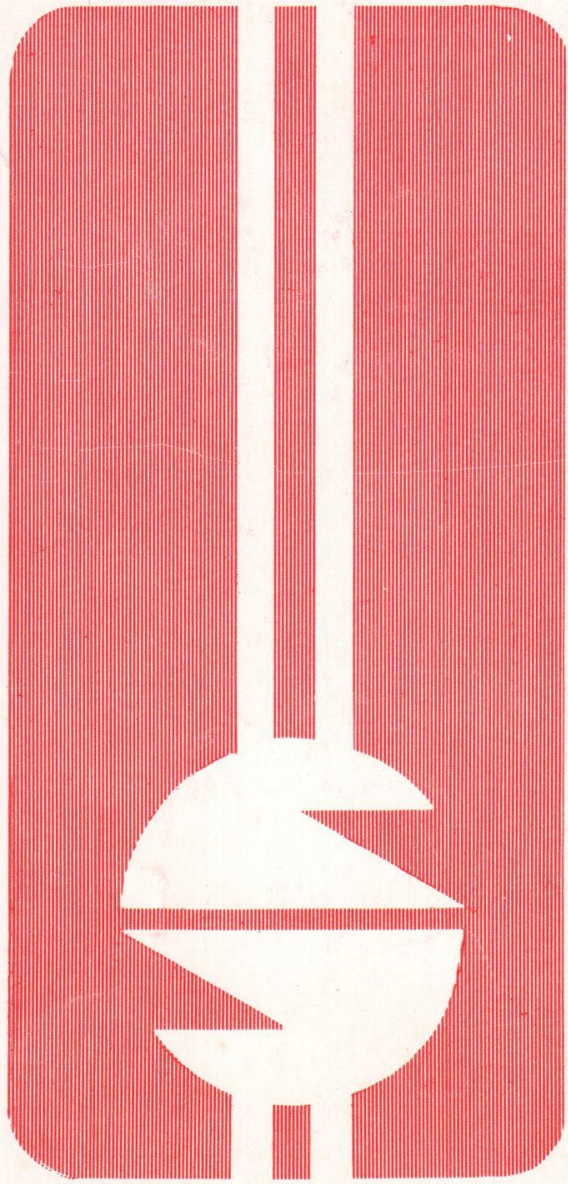

ano 4 
REITOR: Prof. Francisco Ferraz

DIRETOR DA FACULDADE DE CIÊNCIAS ECONÔMICAS:

Prof. Edgar Irio Simm

VICE-DIRETOR: Prof. Walter Meucci Nique

CHEFE DO DEPARTAMENTO DE CIENCIAS ECONO̊MICAS:

Prof. Ernani Hickmann

CONSELHO EDITORIAL: Prof. Pedro Cezar Dutra Fonseca (Presidente)

Prof. Achyles Barcelos da Costa

Prof. Carlos Augusto Crusius

Prof. Claudio Francisco Accurso

Prof. Edgar Augusto Lanzer

Prof. Ernani Hickmann

Prof. Juvir Mattuella

Prof. João Rogério Sanson

Profa. Maria Imilda da Costa e Silva

Prof. Nali de Jesus de Souza

Prof. Nuno Renan L. de Figueiredo Pinto

Profa. Otilia Beatriz Kroeff Carrion

Prof. Paulo Alexandre Sphor

Prof. Rober to Camps Moraes

Profa. Yeda Rorato Crusius

FUNDADOR: Prof. Antonio Carlos Santos Rosa

ANÁLISE ECONÔMICA publica dois números anuais nos meses de março e novembro. $O$ preço da assinatura para 1986 é $\mathrm{Cz} \$ 36,00$, a ser pago através de cheque nominal para "Faculdade de Ciências Econômicas - UFRGS". Aceita-se permuta com revistas congêneres. Aceitam-se, também, livros para elaboração de resenhas ou recensões.

Toda a correspondência, material para publicação, assinaturas e permutas devem ser dirigidas a:

Prof. PEDRO CEZAR DUTRA FONSECA

Revista Análise Econômica

Avenida João Pessoa, 52 - 3 ? andar

90.000 - Porto Alegre (RS) - Brasil 


\title{
COMPETITIVIDADE ENTRE CULTIVOS DE ABASTECIMENTO DO MERCADO INTERNO E EXPORTAÇÃO NO SUDOESTE DO PARANÁ
}

\author{
ARION C. FOERSTER * \\ JUVIR L. MATTUELLA ** \\ JUDAS TADEU G. MENDES ***
}

\section{1 - INTRODUC̣ĀO}

Embora o Brasil detenha um enorme potencial de produção agrícola não deixa de ser paradoxal a situação de escassez de alimentos que o país enfrenta. De um lado tem-se uma vasta disponibilidade de terras agricultáveis; de outro, luta-se com sucessivas altas nos preços dos alimentos advindos da incapacidade de se abastecer o mercado interno com quantidades suficientes dos mesmos. Embora parte desta escassez de oferta deva ser creditada às condições climáticas desfavoráveis que se verificaram em anos recentes, a grande parte da mesma é, entretanto, o resultado de políticas agrícolas praticadas na última década. Tais políticas foram delineadas para favorecer, basicamente, um reduzido número de produtos de exportação - notadamente soja - em detrimento de produtos voltados para mercado interno como arroz, milho, feijão e mandioca. Na década de 70 a soja cresceu, aproximadamente, 560 pontos percentuais acima do crescimento médio observado para os quatro outros produtos. Esta tendência, entretanto, não tem se verificado nos primeiros anos de 80 , pois alguns produtos de abastecimento interno experimentaram sensivel crescimento neste período. Entretanto, a retomada no crescimento da produção de produtos de

* Técnico do Instituto Paranaense de Desenvolvimento Econômico Social - IPARDES

* * Professor da Universidade Federal do Rio Grande do Sul

*** Professor da Universidade Federal do Paraná

ANÁLISE ECONÓMICA

ANO 4

No 6

MARÇO/86

p. $89-99$ 
mercado interno não foi suficiente para garantir um suprimento satisfatório de alimentos, pelo menos aos níveis desejados (2).

Segundo Homem de Mello (6), a redução na disponibilidade de alimentos tem contribuído para alterar os níveis de equilíbrio alimentar da populaçâo do país. Produtos como o arroz, feijão, batata, mandioca e milho, de importante contribuição calórica e protéica, apresentaram uma queda de $25 \%$ na disponibilidade por habitante/dia no período 67/79. Isto provocou uma queda de cerca de $2,07 \%$ ao ano para o agregado calórico e de $2,27 \%$ para o protéico por habitante/dia (2). Outro fator que tem colaborado na queda do padrão nutricional da população é a constante elevação dos preços dos alimentos básicos acima do índice utilizado para corrigir os salários. Em Curitiba, por exemplo, enquanto o custo da alimentação no domicílio - com peso de 0,45 na composição do custo de vida da classe assalariada - aumentou em $10.094 \%$ entre 1978/84, o Indice Nacional de Preços ao Consumidor (INPC) cresceu apenas $6.448 \%$ (2). Esta situação não foi diferente da observada em Capitais de outros Estados brasileiros.

Deve-se destacar, ainda, que a crescente urbanização do país tem contribuído, também, para o agravamento do abastecimento interno. O fluxo migratório que tem deixado o campo, embora mal remunerado nas cidades, tem pressionado a demanda por alimentos. Além disso, se esta força de trabalho que sistematicamente tem deixado o setor primário não for compensada por outros fatores de produção a própria oferta de alimentos poderá ser afetada por este fenômeno.

Em síntese, a problemática do abastecimento alimentar urbano envolve uma gama de fatores que de uma ou de outra forma estão inter-relacionados. Face a isto, o presente trabalho visa examinar a competitividade dos produtos alimentares vis a vis com os de exportação, a nível de produção, para avaliar as possibilidades de expansão dos mesmos. Para tanto, optou-se como área de estudo a micro-região Sudoeste Paranaense. A escolha recaiu sobre esta região por apresentar diversas vantagens, tais como: produz tanto produtos de mercado interno como de exportação; possui cerca de 7\% da área agrícola em descanso; a estrutura fundiária é representativa das pequenas propriedades cuja produção é basicamente voltada para o mercado interno e, além disso, ela tem a maior área voltada à produção de alimentos do Estado do Paraná. 


\section{2 - MODELO DE ANÁLISE}

A produção agrícola, em determinada região, pode ser visualizada como sendo um conjunto de atividades desenvolvidas em unidades econômicas (estabelecimentos rurais) que usam os recursos produtivos nelas existentes. Cada uma destas atividades representa um processo produtivo, composto por diversas fases nas quais são definidos os recursos e as quantidades dos mesmos que são utilizados para que no final se realize a produção. Embora estas atividades representem processos autônomos, elas estão interligadas entre si pois disputam o mesmo volume de recursos disponíveis. Seguindo-se esta abordagem e assumindo plena mobilidade de recursos interestabelecimentos, desenvolveu-se um modelo de programação matemática que permite determinar a competitividade de cada uma das atividades programadas pelo uso dos recursos disponíveis não nos estabelecimentos individualmente, mas sim na região como um todo. Além disso, o modelo permite simulações tanto no volume de recursos como na rentabilidade de cada um dos sistemas produtivos modelados. Em forma compacta, o modelo utilizado pode ser descrito como segue:

Max. $M B=P^{\prime} Q-C^{\prime} X$

Sujeito a:

$$
\begin{aligned}
& A X \leqslant B \\
& D X \geqslant 0 \\
& Q \geqslant \bar{Q} \\
& Q, X \geqslant 0
\end{aligned}
$$

onde:

$\mathrm{MB}=$ margem bruta;

$\mathrm{P}=\mathrm{um}$ vetor $\mathrm{i} \times \mathrm{I}$ de preços dos " $\mathrm{i}$ " produtos agrícolas produzidos;

$\mathrm{Q}=\mathrm{um}$ vetor $\mathrm{i} \times \mathrm{I}$ de quantidades dos produtos agrícolas produzidos;

$\mathrm{C}=u \mathrm{~m}$ vetor $\mathrm{j} \times \mathrm{I}$ de custos de produção das atividades agrícolas (processos produtivos);

$\mathrm{X}=\mathrm{um}$ vetor $\mathrm{j} \times \mathrm{I}$ das " $\mathrm{j}$ "' atividades agrícolas utilizadas na produção dos " $\mathrm{i}$ " produtos;

$A=$ uma matriz $k \times j$ de coeficientes técnicos de produção das atividades agrícolas;

$\mathrm{B}=\mathrm{um}$ vetor $\mathrm{k} \times \mathrm{I}$ de disponibilidade de recursos produtivos existentes na região;

$D=$ uma matriz $\mathrm{i} \times \mathbf{j}$ de coeficientes de transformação de unidades da atividade de produção (ha) em unidades de produtos agrícolas $(\mathrm{kg})$; 
$\overline{\mathrm{Q}}=$ um vetor $\mathrm{i} \times 1$ de limites inferiores de produção para os " $i$ " produtos produzidos (restrições de flexibilidade).

Foram programados os produtos arroz, feijão, milho, mandioca, trigo como de abastecimento interno; soja como cultura de exportação; suinocultura, por ser uma opção para o aproveitamento do milho e mandioca, foi considerada tanto para o abastecimento do mercado interno como para exportação. As atividades de lavoura foram modeladas para três tipos de solos e três processos de produc̣ão: manual, tração animal e motomecanizado.

As restrições quanto aos recursos estão condicionadas ao ni. vel de disponibilidade regional e se definem através de quantidades fixas dos fatores produtivos. São de nove tipos: terra, mão-de-obra, horas de trabalho trator, horas de trabalho animal, horas de trabatho máquinas de colheita, crédito, estoque de bens produzidos, capacidade em empréstimo e área mínimas para lavouras.

O fator terra, levantado a partir de estudo do IPARDES, (3) foi subdividido em três tipos, considerados tanto para o período de verão quanto de inverno. A disponibilidade imputada ao modelo foi de 656.558 ha, correspondendo à área de planejamento.

Mão-de-obra, horas de trabalho trator, animal e máquinas de colheita foram considerados como um fluxo anual.

O crédito contou com duas restrições, uma para capital de giro e outra para investimento. Essas restrições foram deixadas livres e o modelo determinou os níveis necessários.

Para evitar especialização na produção, incluiu-se no modelo níveis mínimos para os produtos de lavoura programados. Estes níveis foram obtidos considerando-se as áreas mínimas colhidas no período 1970/82 para cada produto, com excecão para a soja, que foi considerada a área média verificada no período e as respectivas produtividades.

A margem bruta (função objetivo) representa a diferença entre o valor da produção (preços $x$ produção) e os custos variáveis. Calculou-se a margem bruta para cada uma das atividades de lavoura programadas bem como para a suinocultura.

Para atender aos objetivos, o modelo foi rodado uma vez na sua forma original, a fim de se obter uma solução básica. Posteriormente, procedeu-se a parametrização do preço de cada um dos produtos selecionados para analisar a sensibilidade dos mesmos em relação a este parâmetro. 


\section{3-RESULTADOS}

a) Modelo básico

Os empreendimentos que constaram da solução ótima do modelo básico e o respectivo valor são apresentados na tabela 1 . A cultura da soja, dentre aquelas programadas, mostrou ser a mais rentável da região. Esta cultura, em termos de rentabilidade, domina todos os outros cultivos de verão. No período de inverno as meIhores opç̃os foram o trigo e o feijão da seca. Os demais cultivos fizeram parte da solução ótima somente porque foi estabelecido para eles um limite mínimo a ser produzido e todos eles ficaram neste limite.

TABELA 1 - AREA E PRODUÇÃO DAS ATIVIDADES PRODUTIVAS COMPONENTES DA SOLUÇĀO ÓTIMA DO MODELO BẢSICO PARA A MICRORREGIÃO DO SUDOESTE PARANAENSE

\begin{tabular}{lrr}
\hline ATIVIDADES & $\begin{array}{c}\text { ÁREA } \\
\text { (ha) }\end{array}$ & $\begin{array}{c}\text { PRODUÇÃO } \\
(\mathrm{t})\end{array}$ \\
\hline Arroz & 11.589 & 15.066 \\
Feijão das águas & 70.635 & 68.940 \\
Feijão da seca & 233.427 & 57.106 \\
Mandioca & 7.216 & 103.889 \\
Milho & 162.045 & 315.794 \\
Soja & 405.073 & 766.253 \\
Trigo & 415.914 & 465.254 \\
Suinos & 0 & 0 \\
\hline
\end{tabular}

FONTE: Dados da Pesquisa

A produção de suínos - livre no modelo - não mostrou ser competitiva. Isto pode ser explicado pelo fato de que esta atividade utiliza milho e mandioca e como estas são menos rentáveis do que a soja, afetaram, indiretamente, a produção de suínos.

A combinação de atividades apresentada na tabela 1, que maximiza a renda bruta da região, utiliza toda a terra programada no modelo. Este recurso é restritivo tanto para os cultivos de verão como os de inverno. Em contrapartida, a mão-de-obra é subutilizada em todos os períodos. O pico de uso da mesma ocorre em setembro e outubro, com utilização de $61 \%$ e $97 \%$ da disponibilidade, respectivamente. Nos demais o uso da mão-de-obra não chega a alcançar $50 \%$ do disponível programado no modelo. 
No que tange ao item capital, representado principalmente pelas máquinas e equipamentos, observou-se que horas trator foi a restrição mais efetiva. $\mathrm{O}$ uso do trator ocorre com maior intensidade no período do preparo do solo para o cultivo do trigo, março a maio, chegando neste último mês à plena utilização da disponibilidade. Nos demais meses do ano, existe uma alta ociosidade com es. te fator. A colheitadeira, por outro lado, é extremamente subutilizada. Pela solução ótima do modelo, o pico de uso deste equipamento atinge apenas $32 \%$ das horas disponíveis, ficando, portanto, cerca de $70 \%$ de seu potencial sem utilização. Esta grande ociosidade com as colheitadeiras pode estar relacionada com a facilidade com que no passado se obtinha crédito agrícola subsidiado, incentivando os produtores a adquirirem equipamentos acima de suas reais necessidades.

O emprego de animais de trabalho, por ser um fator mais flexível dentro dos empreendimentos agrícolas programados, apresentou dois picos de utilização: janeiro a março, que corresponde ao preparo do solo para os cultivos de inverno e agosto a outubro, que coincide com o início das lavouras de verão. Neste último período de pico a utilização dos animais de trabalho chegou a ser de $90 \%$ da disponibilidade, enquanto que nos demais períodos foi menor. Isto mostra que entre os processos produtivos dos cultivos de verão, os mais rentáveis são aqueles que usam intensivamente a tração animal.

\section{b) Parametrização dos preços}

Diversos critérios foram levados a efeito na mudança dos parâmetros dos produtos programados. As atividades que compuseram a solução ótima com valores acima do mínimo estabelecido, tiveram seus preços reduzidos em $10 \%$ e $25 \%$, respectivamente. Os cultivos que entraram na solução ótima apenas nos limites mínimos previamente estabelecidos, tiveram seus preços parametrizados em níveis de $10 \%, 25 \%, 50 \%$ e $75 \%$ acima dos iniciais. Para a suinocultura, que não estava atrelada a nenhuma restrição de produção mínima e que não fez parte da solução ótima, adotou-se preços $15 \%$ e $20 \%$ superiores àqueles do modelo básico.

As parametrizações foram feitas tomando-se uma atividade de cada vez. Os resultados da análise de sensibilidade aos preços são apresentados na tabela 2 . 
Aumentando-se o preço do arroz em até $10 \%$ não haveria alteração na solução do modelo básico. Isto significa que para este produto competir com os demais, é necessário que seu preço seja pelo menos $10 \%$ acima daquele auferido pelos produtores na safra $83 / 84$ na região estudada. Uma elevação de $15 \%$ neste preço, todavia, acarreta um aumento de $30 \%$ na área cultivada com este produto, com igual efeito na produção. Em contrapartida, se o preço básico fosse aumentado em $50 \%$, o arroz predominaria sobre os cultivos que disputam a terra no verão e sua produção aumentaria em $1.248,0 \%$. E interessante notar que a este nível de preços, o arroz competiria com os demais produtos pelas melhores terras e com o milho, pelas terras menos nobres.

De maneira geral, os resultados da parametrização indicam que poderia haver uma resposta positiva de produção por parte dos produtores a variações no preço do arroz, e, ainda, a oferta deste produto seria relativamente elástica.

O cultivo do feijão das águas, contrariamente ao do arroz, é menos sensível a alterações no preço. Aumentos de até $25 \%$ no preço básico do feijão verificados na safra $83 / 84$ na região não levariam a nenhuma mudança na produção deste produto. Se, entretanto, o preço fosse aumentado neste percentual, o cultivo do feijão das águas passaria a competir com os demais cultivos de verão e teria um acréscimo de $95,5 \%$ tanto na área plantada como na produçẫo. Para um preço $50 \%$ acima do básico, a área cultivada com esta atividade aumentaria em $299,2 \%$ enquanto que haveria um acréscimo de $194 \%$ na produção. A diferença entre o acréscimo na área plantada e produção pode ser explicado pela reestruturação na distribuição espacial dos cultivos. Na medida em que a área cultivada se expandiu, a produção se deslocou para solos menos nobres, ocasionando uma queda da produtividade média.

O feijāo da seca, como é cultivado no período de inverno, tem poucas culturas que com ele competem pelo fator terra. Assim, mesmo que o preço fosse reduzido em até $25 \%$, este cultivo ainda seria competitivo. Com redução de preço acima de $25 \%$, a área liberada pela retração no cultivo do feijão da seca ficaria ociosa, pois ela ocorreria em solos com baixa fertilidade. Para aumentos no preço do produto acima de $25 \%$, esta atividade ocuparia toda a área de inverno disponível, reduzindo aos limites mínimos a produção de trigo e mandioca.

A mandioca, por ser uma cultura anual, compete tanto com os cultivos de inverno como os de verão. Entretanto, o acirramento da competição ocorre no verão, visto ser este o período em que 
TABELA 2 - SENSIBILIDADE DA PRODUÇÃO AGRÍCOLA

\begin{tabular}{|c|c|c|}
\hline PRODUTO & $\begin{array}{c}\text { Mudanças Percentuais } \\
\text { no Preço Básico }\end{array}$ & $\begin{array}{l}\text { Variações percentuais nas } \\
\text { Quantidades Produzidas } \\
\text { em relação ao modelo bá. } \\
\text { sico. }\end{array}$ \\
\hline Arroz & $\begin{array}{l}+10,0 \\
+25,0 \\
+50,0\end{array}$ & $\begin{array}{r}0,0 \\
+308,0 \\
+1.248,0\end{array}$ \\
\hline Feijåo das Águas & $\begin{array}{l}+10,0 \\
+25,0 \\
+50,0\end{array}$ & $\begin{array}{r}0,0 \\
+95,0 \\
+194,0\end{array}$ \\
\hline Feijão da Seca & $\begin{array}{l}-25,0 \\
-10,0 \\
+10,0 \\
+25,0 \\
+50,0\end{array}$ & $\begin{array}{r}-96,0 \\
-8,0 \\
0,0 \\
+23,0 \\
+168,0\end{array}$ \\
\hline Mandioca & $\begin{array}{l}+10,0 \\
+25,0\end{array}$ & $\begin{array}{l}+1.409,0 \\
+1.950,0\end{array}$ \\
\hline Milho & $\begin{array}{l}+10,0 \\
+25,0 \\
+50,0 \\
+75,0\end{array}$ & $\begin{array}{r}0,0 \\
0,0 \\
+14,0 \\
+172,0\end{array}$ \\
\hline Soja & $\begin{array}{l}-10,0 \\
-25,0\end{array}$ & $\begin{array}{l}-25,0 \\
-67,0\end{array}$ \\
\hline Trigo & $\begin{array}{l}-10,0 \\
-25,0\end{array}$ & $\begin{array}{l}-11,0 \\
-93,0\end{array}$ \\
\hline Suinos & $\begin{array}{l}+10,0 \\
+15,0 \\
+20,0\end{array}$ & $\begin{array}{r}0,0 \\
- \\
+832,0\end{array}$ \\
\hline
\end{tabular}

FONTE: Dados da Pesquisa.

o leque de opções é maior. Porém, esta cultura se mostrou extremamente sensível a variações no seu preço, pois com $10 \%$ de aumento do mesmo ela já se torna competitiva. Para aumento nos preços entre $10 \%$ e $25 \%$ esta cultura forçaria os demais a se fixarem no limite mínimo estabelecido e ocuparia a área assim liberada.

O milho não mostrou ser um empreendimento competitivo na região estudada. Para que ele passe a ser mais rentável do que alguns dos demais cultivos de verão, é necessário que seu preço básico aumente além de $25 \%$. Parametrizando-se os preços no intervalo entre $26 \%$ e $50 \%$ acima do preço base, a produção física cresce em 
$14,0 \%$ sem, entretanto, modificar a área cultivada. Isso ocorre via realocação de cultivos, passando a produção de milho para solos mais produtivos, enquanto que a soja seria deslocada para solos menos férteis. Para que o milho ocupe o máximo da área disponível é necessário que seu preço base tenha um acréscimo em mais de $50 \%$.

A soja, ao contrário do milho, é bastante sensível a variações de seu preço. Para quedas no preço base de até $10 \%$, implicaria numa redução da área cultivada com esta leguminosa em cerca de $25 \%$. Para que esta cultura se fixe no mínimo estabelecido no modelo é necessária uma queda no preço entre $11 \%$ e $25 \%$. Por outro lado, para aumentos no preço não haveria resposta de produção, visto que este cultivo já na solução ótima do modelo básico ocupa toda a área disponível. Assim, a curva de oferta é perfeitamente inelástica para preços acima daquele verificado no safra 83/84.

A situação do trigo é parecida com a da soja, pois aumentos em seu preço não encontram resposta positiva na produção. Ocorre que a produção de trigo, na solução ótima do modelo básico, esgota a disponibilidade de horas trator no mês de maio, assim para ampliar sua área cultivada somente é possível se esta restrição for relaxada. Desta maneira, parametrizações do preço de trigo para valores superiores ao nivel básico tornariam as soluções redundantes. Porém, se o preço baixar entre $11 \%$ a $25 \%$, a produção de trigo cai para o limite mínimo imposto no modelo. Quedas no preço inferiores a $10 \%$ provocam pequenas retrações na oferta de trigo, pois a produção deste cereal tenderia a se deslocar das terras mais produtivas para aquelas menos férteis.

A produção de suínos, aos preços vigentes na safra agrícola 83/84, não entrou na soluçăo ótima do modelo básico. Este empreendimento somente se mostra competitivo com os demais se o preço base for aumentado em pelo menos $10 \%$. Entretanto, mesmo para aumentos de preços de até $15 \%$, o nível da atividade na solução ótima é bem inferior à produção histórica da região.

\section{3 - CONCLUSŌES}

Os resultados da análise, embora devarn ser tomados com cautela face à abrangência do modelo utilizado, sugerem que, se a eficiência produtiva fosse a meta a ser atingida, a região tenderia a se especializar no cultivo de uns poucos produtos: feijão, trigo e soja. Os produtos de abastecimento do mercado interno - feijão e trigo 
somente são competitivos no período de inverno, onde as opçōes de cultivos são bastante reduzidas, enquanto que no verão, onde o leque de alternativas é maior, a soja - cultivo de exportação - domina em rentabilidade os demais.

A predominância da soja sobre as culturas alimentares - ar. roz, feijão das águas, milho e mandioca - evidencia o resultado das políticas agrícolas praticadas até recentemente no país. A facilidade de crédito, a pesquisa agrícola, os subsídios aos insumos modernos e o serviço de extensão incentivaram indiscutivelmente os produtos de exportação em detrimento daqueles de abastecimento interno. Assim, para que a produção de alimentos volte a competir com os demais produtos agrícolas é necessário delinear um conjunto de políticas que revertam a tendência até agora verificada. Conforme foi verificado na análise dos resultados, aumentos nos preços pagos aos produtores tornariam os cultivos mais atraentes e, conseqüentemente, teriam efeitos positivos sobre a produção de alimentos. Estes efeitos, contudo, seriam diferentes de uma cultura para outra; seriam mais efetivos no arroz, mandioca e feijão das águas e menores no milho.

Embora não tenha sido explicitamente examinado no modelo, os resultados das soluções ótimas sugerem que existe grande ociosidade de fatores produtivos na região estudada. O superdimensionamento dos bens de capital - trator, automotriz e outros equipamentos - pode ser ainda o reflexo da política de crédito agrícola que vigorou em passado recente. O crédito subsidiado, aliado à pesquisa direcionada ao desenvolvimento de técnicas agrícolas baseadas em energia abundante e barata, devem ter sido os principais fatores que levaram os produtores a optarem por tecnologias intensivas em capital, embora estes processos produtivos, face às novas relações de preços, não sejam economicamente tão eficientes como outros em que a tração animal predomina. Aliás, este resultado aponta um possivel direcionamento que deve tomar a pesquisa agrícola.

Em resumo, se o objetivo for o de aumentar de forma eficiente a produçẫo para abastecer o mercado interno, é necessário direcionar a política agrícola de tal forma que beneficie a produção para este fim. Para tanto, é necessário elaborar um conjunto de medidas que visem a ampliar a margem de ganho do produtor, seja pelo aumento na receita via mecanismo de preços ou ganhos na produtividade pelo redirecionamento da pesquisa agronômica. 


\section{4 - BIBLIOGRAFIA}

1. ABASTECIMENTO E CARESTIA. Análise Conjuntural, Curitiba, IPARDES - Fundação Edison Vieira, 5(6):5-7, jun-jul. 1983.

2. FOERSTER, Arion C. Analise Comparativa de Alternativas de Produção: $O$ Caso das Culturas Alimentares no Sudoeste do Paraná, Porto Alegre, IEPE/UFRGS, Tese de Mestrado em Economia. Não publicada.

3. INSTITUTO PARANAENSE DE DESENVOLVIMENTO ECONÔMICO E SOCIAL IPARDES - Fundação Edison Vieira, Possibilidades agroecológicas da expansão das culturas alimentares no Estado do Parana. Curitiba, 1984 . Não Publicado.

4. LANZER, Edgar Augusto. Programação Linear: conceitos e aplicações. Rio de Janeiro, IPE/INPES, 1982. 270p.

5. MATTUELLA, Juvir L. Produção de álcool e utilização da mão-de-obra rural no sul do Brasil. Revista de Economia Rural. Brasilia, $21(7): 71(1): 71-89$, jan-mar 1983.

6. MELO, Fernando Homem de. A contribuição da agricultura: alimentos, exportações e energia. Revista de Economia Rural, Brasilia, 20(2) :252-40, 1982.

7. MENDES, Judas Tadeu G. Análise da sensibilidade da produção agropecuária às alterações de alguns parâmetros de modelos de programação linear para o município de lolanda - PR. 1970/71. Porto Alegre, IEPE/UFRGS. 1975, Tese de Mestrado. Não publicada. 